\title{
ERRATUM
}

\section{Erratum to: Application of Polymerase Chain Reaction to Detect HIV-1 DNA in Pools of Dried Blood Spots}

\author{
Vemu Lakshmi $\cdot$ Talasila Sudha $\cdot$ Rakhi Dandona \\ G. Anil Kumar $\cdot$ Lalit Dandona
}

Published online: 8 July 2011

(C) Association of Microbiologists of India 2011

Erratum to: Indian J Microbiol (2011) 51(2):147-152

DOI 10.1007/s12088-011-0135-0

Unfortunately the author names given before as "Dandona Rakhi" and "G. Anilkumar" were spelled out wrong by mistake, these should read "Rakhi Dandona" and "G. Anil Kumar" as now given.

The online version of the original article can be found under doi: 10.1007/s12088-011-0135-0.

V. Lakshmi $(\varangle) \cdot$ T. Sudha

Nizam's Institute of Medical Sciences, Hyderabad, AP, India

e-mail: vemulakshmigorthi@gmail.com

T. Sudha

e-mail: s_talasila@hotmail.com

R. Dandona · G. Anil Kumar · L. Dandona

Public Health Foundation of India, New Delhi, India

e-mail: rakhi.dandona@phfi.org

L. Dandona

e-mail: lalit.dandona@phfi.org

L. Dandona

Institute for Health Metrics and Evaluation,

University of Washington, Seattle, Washington, USA 